could be less likely to spend time with him, feeding him, and that if it prolonged life, it would be for more grave infections to be repeated. We discussed that, with his memory loss, it was easier for him than for me not to look forward and back. I spoke to our daughter, who was a first year house surgeon in the North Island. She talked about her experiences of PEG tubes-about a man with cancer of the oesophagus who had had terrible excoriation around his gastrostomy site, and about a woman who had had the procedure after a stroke, a decision our daughter had felt morally uncertain about.

My husband and I have had further talks about this. Well, I talked and deciphered his responses. In the last he said he didn't want it. He said he was not frightened by the prospect of his death. Our son and I talked to the registrar again, the day of his discharge. "What shall we do the next time he gets an infection? The after-hours doctor won't know him and will want to admit him to hospital. I won't want to take a different position unsupported, and the nurses will be helpful but unsure of their ability to cope. Then, when he goes to hospital, that will be seen as an indication for treatment." Yes, she said, he should be admitted if the diagnosis is uncertain, but not necessarily for treatment. There, with better diagnostic facilities, it will be clearer what we are dealing with. Depending on the diagnosis, he can be treated with antibiotics or cared for in a side room in the hospital with experienced staff and us.
This very experienced registrar had first met my husband when she was a medical student. Now she had, over several conversations, helped to give a shape to the future which all of us could make some sense of. The therapeutic imperative, exercised by many different doctors, each focusing on the patient in front of them, provides a kind of certainty to which patients and relatives can submit. But sometimes it becomes a monster and pushes patient and relatives beyond endurance.

\section{Epilogue}

After this account was written, my husband put on some weight, helped by our extra efforts to feed him. Nine months later he died. He became unable to swallow almost entirely in the couple of weeks before he died. He was kept hydrated with subcutaneous fluids. His oft repeated "How long have I got?" could be tentatively answered. He was aware of his last days and hours and all his family was with him. In the end it was not necessary for him to go to the public hospital. The nurses at the geriatric hospital kindly shared his care with the family.

I thank Ruth and Tom Cunningham for comments on the draft manuscript.

Competing interests: None declared.

\title{
Mind over matter?
}

Lucy and Dan (not their real names) were expecting their first baby in 1992, when Lucy was 26 . Hypertension resulting from pregnancy meant that labour had to be induced at 37 weeks' gestation, and a girl of $2.8 \mathrm{~kg}$ was born by normal delivery. Twelve months later Lucy had another girl of the same weight by normal delivery. Twenty months later a boy saw first light. He weighed a bit more but still came normally. Nearly three years later Lucy was pregnant again. This time the hypertension returned and, with it, intrauterine growth restriction. At 35 weeks' gestation the Doppler studies weren't reassuring. A boy weighing $2.3 \mathrm{~kg}$ was delivered by caesarean section.

Over the next year Lucy had two first trimester miscarriages. Then at 31 weeks into her seventh pregnancy (already complicated by placenta praevia) her membranes ruptured and premature labour ensued. Her fifth child was delivered by emergency caesarean section-the smallest baby, a girl of $1.9 \mathrm{~kg}$. She did well. Next was Lucy's millennium baby: in June 2000 at 36 weeks a girl was delivered by caesarean section, as blood pressure problems had recurred.

One year later, with Lucy again pregnant, she and Dan decided that this, the ninth pregnancy, would be the last. In June 2001 she was delivered of a $3.1 \mathrm{~kg}$ healthy boy, her seventh child and fourth caesarean. Both uterine tubes were doubly tied and the mid-section excised (by the Pomeroy technique) and sent to pathology for confirmation.

So with seven healthy children, from the newborn son to the eldest girl of nine, Dan and Lucy settled to bringing up their large family and making a living.

But-then came the surprise. Less than two years later, Lucy, now 37 , started to feel broody. Specious perhaps, but she wanted another child. The urge was strong; she was thinking of making inquiries about reversing the sterilisation when she realised that her period hadn't arrived. Sure enough, the line showed up in the

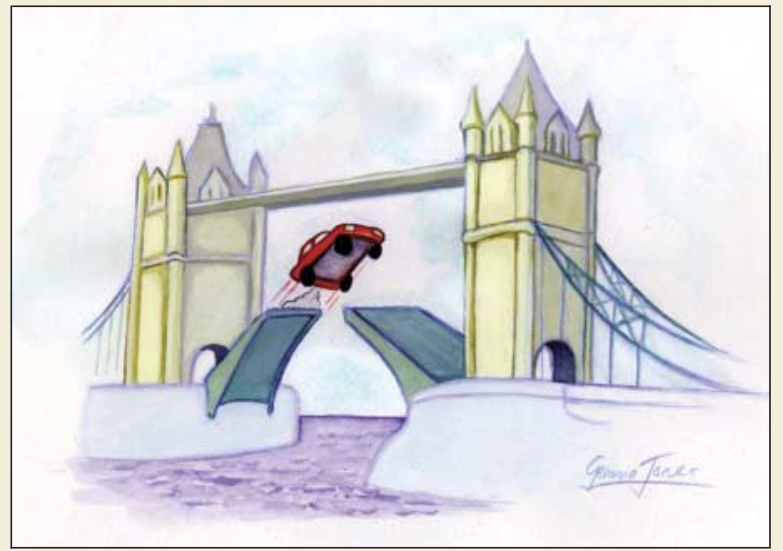

middle window of the test stick, and a scan showed a viable intrauterine pregnancy. Lucy was delighted. After the baby boy was safely delivered by caesarean section, we took a close look at the remnants of the tubes. They hadn't re-anastomosed, and the proximal and distal severed ends were free on both sides. This time we took out both tubes in their entirety, and the pathologist once again confirmed the clinical appearance.

Did willpower help the oocyte to jump the gap? Isn't it wonderful how nature can work miracles-and that, when surprises occur, not everyone wants to blame somebody?

Alastair C McKelvey (alastairmckelvey@doctors.org.uk) specialist registrar, obstetrics and gynaecology,

James C Dornan consultant obstetrician and gynaecologist, Royal Jubilee Maternity Service, Belfast 